\title{
A RELEVÂNCIA DA CONSTRUÇÃO DO PPP seus tópicos e sua flexibilidade na prática profissional
}

\author{
Marcele Barbosa Figueiredo 1 \\ Arlete de Freitas Botelho ${ }^{2}$
}

\begin{abstract}
Resumo: O Projeto Político-Pedagógico (PPP) é o documento orientador das ações que devem ocorrer na instituição escolar, devendo estar presente em todas elas. Ele deve servir como orientador das práticas escolares, demonstrando seu contexto social sendo, portanto, flexível em suas considerações, para que durante sua execução possa sofrer adaptações no decorrer do ano letivo. Considerando sua eficácia na atuação docente, assim como suas colaborações no processo de ensino e aprendizagem, salientadas nas referências bibliográficas consultadas, a presente pesquisa buscou analisar de que modo esse projeto interfere nas diferentes funções desempenhas pelos docentes na escola (diretor, coordenador ou professor). Para verificar como ocorre a construção e a execução do PPP utilizou-se como instrumento de pesquisa um questionário, contendo seis questões discursivas, aplicado em três escolas do município de Formosa-GO, sendo uma pública, uma privada particular e uma privada confessional, tendo cada uma delas participado com seis representantes, que desempenhavam as funções ora citadas. Pode-se perceber que nenhuma das instituições constrói e executa de maneira completa, o seu projeto. O PPP é um documento que deve envolver a todos, com o intuito de discutir, elaborar e executar o planejamento, assim como realizar uma avaliação constante para saber onde e como proceder às alterações - caso se perceba que não mais está surtindo o efeito desejado - para a busca da qualidade de ensino.
\end{abstract}

Palavras-chave: PPP. Execução. Prática pedagógica.

\section{THE RELEVANCE OF THE CONSTRUCTION OF THE PPP its topics and its flexibility in professional practice}

\begin{abstract}
The Political-Pedagogical Project (PPP) is the guiding document of the actions that must occur in the school institution, and must be present in all of them. It should work as the guiding of school practices, demonstrating its social context and therefore, being flexible in its considerations, so that during its execution during the school year it may undergo adaptations. Considering its effectiveness in teaching, as well as its collaborations in the teaching and learning process highlighted in the bibliographical references consulted, the present research sought to analyze how this project exerts influence in the teaching activity carried out in the different roles performed by the teachers during in the school (director, coordinator or teacher). In order to verify how PPP construction and execution takes place, a questionnaire, containing six discursive questions was used as a research instrument, applied in three schools in the city of Formosa-GO, one public, one private and one confessional, in each one of them six representatives attended and performed the aforementioned roles. It can be seen that none of the institutions fully completes the construction and execution of the project. The PPP is a document that should involve everyone in order to discuss, elaborate and execute the planning,
\end{abstract}

\footnotetext{
1 Licenciada em Pedagogia pela Universidade Estadual de Goiás - Campus de Formosa. E-mail: marcelebarbosafigueiredo@gmail.com

${ }^{2}$ Doutora em Políticas Públicas e Gestão da Educação - UnB (2015) e Mestre em Gestão Econômica do Meio Ambiente - UnB (2004). Docente da Universidade Estadual de Goiás - UEG. E-mail: arletebotelho@uol.com.br
} 


\section{REVISTA ELETRÔNICA \\ DA GRADUAÇÃO/PÓS-GRADUAÇÃOO EM EDUCAÇÃO}

UFG/REJ

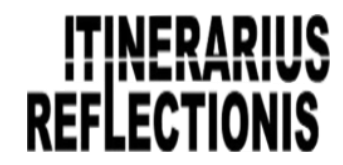

ISS N. 1807-9342

Volume 14, N. 2, 2018

as well as perform a constant evaluation to know where and how to make the changes - in case one realizes that the desired effect is no longer being accomplished-, for the pursuit of quality teaching.

Keywords: PPP. Execution. Pedagogical practice.

\section{INTRODUÇÃO}

O Projeto Político-Pedagógico é fundamental para o bom funcionamento da escola, uma vez que norteia as ações pedagógicas no ambiente educativo. $\mathrm{O}$ documento deve estar presente em todas as instituições de ensino, buscando atender o contexto individual de cada uma, além do importante papel de estabelecer mais vínculos entre a escola e a sociedade.

Para o bom funcionamento institucional, o PPP deve ser construído de forma coerente, já que servirá como base para a atuação anual, mesmo sendo passível de adaptações nesse período, exercendo o princípio da flexibilidade na autonomia escolar. Nele devem constar todas as informações da escola, seus ideais, histórico, contexto social, assim como suas fragilidades e fortalezas, para que ocorra um bom funcionamento da instituição.

Sem a participação dos envolvidos na comunidade escolar o projeto não alcança seu objetivo de refletir sobre a realidade social. Seus atores devem ser pais, estudantes e pessoas da comunidade, que se empenharão em refletir e dialogar, em conjunto com os funcionários (gestores, docentes e servidores) da escola, sobre o retrato mais fiel da realidade, cujos problemas ou soluções muitas vezes não são percebidos por pessoas internas, mas, quando salientados por outros participantes, adquirem nova dimensão.

Como orientador das práticas, o PPP deve ser construído com a comunidade escolar, buscando atender as necessidades da instituição na qual será executado, com base em documentos oficiais que regulam a sua construção e execução. No entanto, devem ser observadas também as regulamentações próprias, para que consiga orientar o trabalho docente. $\mathrm{O}$ professor deve estar aberto a novas experiências e participar desde o início de sua formulação, para, assim, ter condições de executá-lo conscientemente e, consequentemente, avaliá-lo.

Levando em consideração a relevância e o papel fundamental do PPP e tendo conhecimento de que o professor exerce diferentes funções em uma instituição educacional, surgiu a questão central: de que maneira a concepção que se tem do 


\section{REVISTA ELETRÔNICA \\ DA GRADUAÇÃO/PÓS-GRADUAÇÃOO EM EDUCAÇÃO}

UFG/REJ

\section{ITHERARIIIS REFLCTIONIS}

ISSN. 1807-9342

Volume 14, N. 2, 2018

Projeto Político-Pedagógico exerce interferências no trabalho docente em suas diversas funções?

A partir disso, buscou-se, como objetivo geral, analisar a maneira como o PPP é construído e executado na escola, a partir dos olhares que envolvem os seus gestores (diretores e coordenadores), além dos docentes. Para alcançar esse objetivo, teve-se como pontos específicos de análise: (1) verificar quem participa efetivamente da construção do PPP; (2) perceber como os docentes colocam o PPP em prática durante suas diversas funções na unidade escolar; e (3) averiguar a relevância que esse o documento exerce em sua atuação profissional.

Como metodologia para verificar a realidade encontrada nas instituições, após a busca por referenciais teóricos foi realizada uma pesquisa de campo, com a aplicação de um questionário junto aos diretores, coordenadores e professores, sendo todos pedagogos de uma instituição pública, uma privada particular e uma privada confessional, localizadas na área urbana central do município de Formosa (GO).

Espera-se trazer à tona a realidade frente ao aporte teórico de embasamento para este estudo.

\section{O PPP E SUAS DIMENSÕES}

A educação começou a tomar um rumo mais participativo, buscando ouvir a voz de outras pessoas além das envolvidas no interior da escola, ou pelo menos deveria seguir esse caminho. Ademais, deveria também contemplar uma dimensão que ultrapassasse o princípio de documento burocrático. Essa percepção se fortaleceu a partir da Lei de Diretrizes e Bases da Educação Nacional (LDB) no 9.394, de 1996, em seu artigo 13, Inciso I, ao salientar que uma das atribuições das instituições escolares é "elaborar e executar sua proposta pedagógica" (BRASIL, 1996).

O PPP vem atender a essa determinação ao contemplar, em sua estrutura, as dimensões pedagógica, administrativa, financeira e jurídica, que servem como a base para a formulação de temas que a instituição optar por colocar em sua proposta. A questão pedagógica diz respeito ao que a escola busca e a como pretende atingir os objetivos de uma educação de qualidade, com diminuição de repetências e evasão, entre outros fatores (MEDEL, 2008). 


\section{REVISTA ELETRÔNICA \\ DA GRADUAÇÃO/PÓS-GRADUAÇÃO EM EDUCAÇÃO \\ UFG/REJ}

\section{ITINEPRARIIS \\ REFLECTIONIS}

ISSN. 1807-9342

Volume 14, N. 2, 2018

Com uma prática pedagógica condizente, a instituição consegue alcançar as melhorias que deseja, além de satisfazer o sistema educacional. Ao se dedicar verdadeiramente, a escola consegue propiciar a real construção do conhecimento, formando estudantes críticos, conscientes e criativos, que não sejam somente uma máquina manipulável na sociedade.

Sanches (2007, p. 67) faz referência ao currículo, que, ao ser inserido no PPP, demonstra o que a escola escolheu seguir, já que “[...] a elaboração de um currículo toma forma a partir da concepção de conhecimento que se tem e, de fato de que uma visão mais ampliada resulta da visão de mundo, de sociedade, de homem e de educação que se alcançou até aquele momento". Essa opção da escola deve evidenciar suas necessidades e o tipo de estudante a que ela se propõe formar. Desse modo, na prática, o docente deve seguir o que foi estipulado, buscando atender os anseios sociais e pautando-se no que a escola recomenda. Assim, o trabalho se dá de forma mais ordenada e os resultados alcançados são mais visíveis ao fim do ano.

A parte administrativa diz respeito às características organizacionais da escola relacionadas à parte burocrática, de regulação $^{3}$ e regulamentação ${ }^{4}$ da instituição. Conforme Neves (2008), esse ponto reflete tudo que a instituição deseja quanto à parte estrutural. Aparece aí o modelo de gestão, as atribuições do grupo gestor e também como se dará o relacionamento deste com a sociedade interna e externa. Cabem nessa dimensão também a administração de materiais e o controle interior e exterior que a instituição deverá possuir. Na questão administrativa entra o envolvimento com o todo, sendo essa a parte que gerenciará as outras, que tomará uma linha de frente nas decisões em conjunto, para que as ações consigam fluir da forma mais natural possível. A administração de como a escola se relacionará interna e externamente é um ponto relevante, uma vez que se isso não for bem definido alguns problemas de comunicação podem surgir.

Neves (2008) relata que na parte financeira do projeto busca-se demonstrar os recursos que a instituição recebe e como esta irá aplicá-los em suas necessidades. Tais

3 Segundo Botelho (2016, p. 103), regulação é “[...] a expedição por regras regulatórias, cuja competência cabe ao Poder Executivo, por meio de suas entidades pertencentes à administração direta ou indireta $[\ldots] "$ ".

4 Regulamentação “[...] é a legislação oficial nos diversos espaços das instituições, chegando às normatizações internas [...]" (BOTELHO, 2016, p. 104). 


\section{REVISTA ELETRÔNICA \\ DA GRADUAÇÃO/PÓS-GRADUAÇÃO EM EDUCAÇÃO UFG/REJ}

\section{ITINERPARIIUS REFLECTIONIS}

ISSN. 1807-9342

Volume 14, N. 2, 2018

fontes podem ser recebidas de duas formas diferentes: centralizada ${ }^{5}$ e descentralizada. ${ }^{6}$ O financeiro vai além do dinheiro que a instituição recebe e equivale a todo o recurso patrimonialista $^{7}$ que ela possui. Saber onde e como aplicar os recursos que a escola recebe é fundamental para o seu bom andamento. Tais recursos podem ser obtidos tanto em dinheiro vindo para as contas da escola quanto em arrecadações advindas de fontes diversas, ou bens materiais e serviços prestados para as suas melhorias.

A parte jurídica trata da regulação e regulamentação do PPP, em que as leis e os projetos referentes à educação estão presentes e como a escola deve segui-los. Nesse sentido entra a legalização referente à LDB, aos Parâmetros Curriculares Nacionais (PCN), à Base Nacional Comum Curricular (BNCC), entre outros. Esses são exemplos de documentos institucionais de regulação que norteiam a educação brasileira. As leis a serem seguidas são, de maneira geral, as nacionais, porém, as leis estaduais e municipais também exercem forte influência. A legalização busca estabelecer normas a serem adotadas pelas instituições em âmbito nacional, assim como um aprendizado mínimo a ser alcançado.

Embora o projeto tenha que contemplar as quatro dimensões apresentadas, elas devem ser expostas e tratadas correlacionadamente, buscando, em sua união, atender as demandas da instituição a que se referem, como a adequação curricular e a contextualização, a fim de garantir uma aprendizagem significativa. Não há como tratar cada uma das partes de forma desarticulada, pelo risco de o projeto perder sua essência (MEDEL, 2008).

Depende-se do planejamento pedagógico para a execução financeira e do administrativo para conduzir o processo, porque nada pode ocorrer sem a liberação prévia da gestão. Por fim, o jurídico, com a certeza de que o pretendido está em conformidade com os documentos nacionais que regem a educação brasileira, e ainda, a

5 Os recursos aplicados de forma centralizada ocorrem com mais frequência, dado "[...] por uma instância administrativa (Órgão Executor) à qual a escola está submetida hierarquicamente [...] sob esse formato a escola recebe os recursos de forma indireta, por meio de benefícios, atendendo às suas necessidades relacionadas à estrutura física [...]" (HORTA; RAMIRES; DA VID, 2010, p. 49).

6 Na aplicação descentralizada "[...] é a própria escola que a efetuará [...] os recursos públicos poderão ser utilizados para financiar a aquisição de materiais de consumo e a contratação de serviços de manutenção [...]" (HORTA; RAMIRES; DAVID, 2010, p. 50).

7 O recurso patrimonialista contempla toda a infraestrutura que a instituição possui, as sim como tudo que nela se encontra - prédio, cadeiras, mesas, quadros - e tudo mais que a ela pertencer. 


\section{REVISTA ELETRÔNICA \\ DA GRADUAÇÃO/PÓS-GRADUAÇÃOO EM EDUCAÇÃO}

UFG/REJ

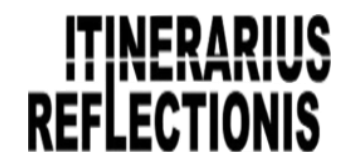

ISSN. 1807-9342

Volume 14, N. 2, 2018

regulamentação, que são os documentos emitidos pelas Secretarias de Educação e pela própria escola e que direcionarão a construção do PPP.

$\mathrm{Na}$ busca por contemplar as dimensões ora citadas, a escola tem autonomia para optar por caminhos diversos e adaptar-se às leis conforme o seu contexto. Isso faz com que o PPP tenha sentido e atenda o conjunto escolar na diversidade que envolve sua construção.

\section{A AUTONOMIA NO PLANEJAMENTO PARTICIPATIVO}

A autonomia $^{8}$ escolar é vista como o momento em que a instituição tem liberdade para definir os caminhos que irá trilhar para atender seus anseios. Essa é a parte em que a escola poderá adaptar-se às leis, para que se enquadre conforme o contexto em que se encontra. Isso a diferenciará das outras, pois tornará possível a apresentação de suas especificidades, porém, caminhando sobre a mesma base nacional comum que as demais.

Segundo Neves (2008), para que ocorra a autonomia na escola os órgãos externos - como os Conselhos e as Secretarias de Educação -, tanto estaduais quanto municipais, devem ser mais flexíveis para a aceitação de mudanças coerentes que a escola venha a propor. Em contrapartida, a escola tem de descentralizar o poder, permitindo que outras pessoas se posicionem diante das decisões a serem tomadas.

Com o fortalecimento do elo entre escola e comunidade os trabalhos ocorrem de forma mais condizente com as necessidades que os estudantes possuem. A autonomia da escola não deve vir somente como uma cobrança da instituição educacional para com o sistema, mas também com mais abertura para a própria sociedade.

A autonomia da instituição deve estar ligada à atitude individual e coletiva cotidiana. Garcia (2004, p. 42) discorre que

[...] a escola pode aproveitar o espaço que está sendo aberto para fortalecer-se, construindo uma identidade própria, configurada, dentre outras formas, na elaboração do projeto político-pedagógico. A outorga da autonomia escolar confere legitimidade e fundamento legal para que as escolas a exercitem. Contudo precisa ser construída paulatinamente no cotidiano escolar, por meio da participação coletiva

8 Define-se autonomia como "direito ou faculdade que tem uma nação de se reger por leis próprias; independência; liberdade moral ou intelectual” (RIOS, 1999, p. 116). 


\section{REVISTA ELETRÔNICA \\ DA GRADUAÇÃO/PÓS-GRADUAÇÃO EM EDUCAÇÃO UFG/REJ}

\section{ITINERPARIIUS REFLECTIONIS}

ISS N. 1807-9342

Volume 14, N. 2, 2018

e da interação comunicativa, defendendo as concepções educacionais que os agentes escolares elegeram para nortear seu trabalho (GARCIA, 2004, p. 42).

A autonomia citada pode ser percebida no cotidiano da escola quando ela tem a possibilidade de reconhecer o que ela necessita e se adequa à sua realidade. Embora seja necessária a autorização da Secretaria de Educação para algumas ações mais específicas, tem-se a disponibilidade de resolver de modo interno a maioria das questões referentes ao que acontece no interior da instituição.

Neves (2008) demonstra que o fato de a escola ser autônoma não desfaz seus compromissos com o sistema educacional, pois ela continua subordinada a ele, obedecendo às diretrizes e às concepções por ele determinadas. A escola não tem competência para criar regulações, no entanto, pode criar seus documentos internos, desde que adequados à regulação do Ministério da Educação (MEC), o que não deixa de ser determinante para que sua autonomia aconteça de forma verídica.

Ao se valer de adaptações, a escola pode realizar as modificações necessárias ao seu plano de ação para que o ensino ocorra de forma mais proveitosa, já que tem a possibilidade de buscar aspectos da realidade local para enriquecer a prática cotidiana. O social interferirá até o ponto em que não ferir a legalidade superior da instituição.

Medel (2008) faz inferência à qualidade de ensino ao citar o PPP como possível caminho para realizar adequações curriculares e para focar determinados aspectos em detrimento de outros, mediante as dificuldades apresentadas pelos estudantes. Porém, a autonomia não deve ser confundida com soberania, ${ }^{9}$ uma vez que a instituição está inserida em outras esferas administrativas e delas depende para manter-se. As leis envolvem soberania, que, por sua vez, está representada pelo Estado.

Ao dar liberdade de a escola definir alguns pontos a serem focados em detrimento de outros devido à sua necessidade, o projeto amplia as possibilidades de um ensino de qualidade e com maior número de estudantes na escola, pois o que for ensinado vai ser adequado às individualidades que a escola possui, dando significado ao que está sendo apresentado em relação à vida dos educandos.

Veiga (2008, p. 13) diz que, como a escola busca atender a sociedade,

9 A soberania é definida como a "qualidade do poder político de um Estado ou de um organismo que não reconhece acima de si nenhuma autoridade" (RIOS, 1999, p. 496). 


\section{REVISTA ELETRÔNICA \\ DA GRADUAÇÃO/PÓS-GRADUAÇÃO EM EDUCAÇÃO UFG/REJ}

\section{ITTERPAPUIS REFLECTIONIS}

ISSN. 1807-9342

Volume 14, N. 2, 2018

[...] todo projeto pedagógico da escola é, também, um projeto político por estar intimamente articulado ao compromisso sociopolítico com os interesses reais e coletivos da população majoritária. É político no sentido de compromisso com a formação do cidadão para um tipo de sociedade $[\ldots]$.

Quando busca atender os interesses sociais, o PPP visa o contexto no qual está inserido, procurando propiciar aos estudantes uma visão ampla da realidade, de maneira que eles possam compreender e modificar seus pensamentos de forma significativa, a ponto de agirem conscientemente na sociedade onde estão imersos. O caráter político visa essa conscientização para a ação, sendo ele demonstrado na gestão democrática.

Até aqui, o aporte teórico sobre o PPP e seus princípios deixam muito clara a visão sobre a dimensão do que realmente deve ocorrer, na prática, nas instituições educacionais. Entretanto, os estudiosos nem sempre revelam a realidade muitas vezes vivenciada pelas escolas. Dessa maneira, buscou-se desenvolver esta pesquisa para verificar a aplicabilidade ou não do tema proposto.

\section{RECURSOS METODOLÓGICOS}

A pesquisa de campo ocorreu em três escolas da área central do município de Formosa-GO, sendo uma instituição pública, uma privada particular e uma privada confessional, que doravante serão identificadas apenas por pública, particular e confessional, como forma de melhor identificar cada categoria administrativa. Tendo uma visão dessas três categorias de instituições, foi possível verificar as semelhanças e diferenças quanto ao modo de construção e percepção do PPP em cada uma. Essa escolha permitiu uma pesquisa mais rica em informações, de modo a comparar percepções do público-alvo selecionado. A identificação das escolas foi preservada, cumprindo as definições da ética na pesquisa.

Como instrumento de investigação foi aplicado um questionário, na modalidade formulário, uma vez que não foram respondidos na presença da pesquisadora, contendo seis questões discursivas, direcionadas aos dezoito professores, três diretores e cinco coordenadores das instituições selecionadas, sendo todos os sujeitos pedagogos. O questionário foi o mesmo para todos os segmentos, para que fossem comparadas e analisadas as percepções sobre o PPP nas diferentes funções exercidas pelo docente em uma escola na prática escolar. Este estudo, ainda que comparativo, pode mostrar quão 


\section{REVISTA ELETRÔNICA \\ DA GRADUAÇÃO/PÓS-GRADUAÇÃO EM EDUCAÇÃO} UFG/REJ

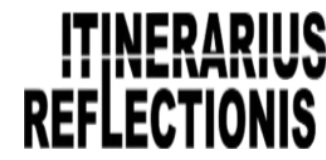

ISS N. 1807-9342

Volume 14, N. 2, 2018

distintos são os pensamentos e as contradições que ocorrem entre as escolas e até mesmo entre os profissionais que a compõem.

Esse instrumento de pesquisa propicia que o indivíduo responda com mais seriedade as questões propostas, pois não se coletam dados que permitam identificá-lo. Com o questionário contendo questões discursivas objetivou-se ter informações mais complexas para análise, por abrir espaço para considerações que não poderiam ser realizadas em perguntas objetivas.

Este trabalho desenvolveu-se com uma pesquisa de campo de natureza qualitativa-descritiva, que consiste "em investigações de pesquisa empírica cuja principal finalidade é o delineamento ou análise das características de fatos ou fenômenos [...]" (MARCONI; LAKATOS, 2003, p. 187). Isso permite que os dados sejam analisados de maneira mais sistemática.

Procurou-se analisar as respostas comparando tanto o tipo de instituição quanto a função que os sujeitos desempenham, buscando perceber as variações de olhares nas categorias estabelecidas. Com isso, conseguiu-se verificar pontos em comum entre os diferentes segmentos, assim como discordâncias e as possíveis razões para que elas ocorram.

\section{RESULTADOS E DISCUSSÃO}

O PPP deve ser construído coletivamente, conforme já discutido, embora essa não seja a realidade de muitas instituições. Em busca de observar como os docentes, nas variadas funções que exercem na escola (diretor, coordenador ou professor), percebem a relevância de se formular o documento em conjunto com pais, alunos, servidores e pessoas da comunidade, questionou-se sobre: a relevância do modo de construção do PPP adotado pela instituição; o PPP em prática na atual função que desempenha na escola; a influência do PPP no planejamento e na postura docente em sua prática pedagógica; a(s) parte(s) do PPP considerada mais relevante para o trabalho pedagógico; o enriquecimento do trabalho do professor, orientando e permitindo a flexibilidade em sua prática; e o sentido do PPP, na prática, na instituição.

Para cada uma das abordagens, tecem-se as análises a seguir, diante das percepções dos sujeitos envolvidos na pesquisa. 


\section{A RELEVÂNCIA DO MODO DE CONSTRUÇÃO DO PPP}

Em relação à relevância do modo de construção do PPP, é preciso evidenciar que a direção da escola pública não respondeu a questão. Isso revela que muitas vezes os profissionais não sabem o motivo pelo qual fazem as coisas, o que denota estarem construindo somente um documento burocrático, cumprindo o que é obrigatório, mas sem saber o motivo pelo qual estão agindo. Ademais, isso certamente se reflete na qualidade educacional.

A coordenação da escola pública enfatizou que como o seu dever é orientar o trabalho de toda a escola, deve ter a participação de todos, para que não ocorram discordâncias. A fala contempla os princípios do PPP, embora ele não seja elaborado por todos que necessitariam estar presentes.

Quanto aos docentes da instituição pública, três concordam que ele deve ser construído coletivamente para que sigam um mesmo objetivo, de forma organizada. Um sujeito não respondeu por desconhecê-lo, alegando estar há pouco tempo na instituição. De fato, a proposição dos três respondentes evidencia que a consciência coletiva ocorre de forma articulada com as ações que se deve ter para conseguir atingir as metas de maneira eficiente.

$\mathrm{Na}$ escola particular, as respostas sobre a construção do PPP dos diferentes segmentos se assemelham. Essa semelhança ocorreu em todas as questões, demonstrando que é uma escola articulada e o trabalho em equipe se dá de forma verdadeira e integrada. Isso é importante para que o ensino se dê de forma linear e contínua, tornando-se um processo de reflexões e ações condizentes. Todos salientam que esse modo de construção é fundamental para que os planejamentos sejam comuns, atendendo o que a comunidade necessita, assim como uma organização no trabalho de todos no processo de ensino-aprendizagem. Um dos docentes argumentou que "quando se trabalha em equipe é importante se sentir responsável pelos resultados do trabalho e pelo alcance das metas estabelecidas" (Informação verbal, ${ }^{10}$ 2017). Isso evidencia que, caso ocorra algum erro, não se tem somente um responsável a apontar, mas um conjunto que assume os problemas e busca a solução com união.

10 "Informação verbal" identifica resposta transcrita literalmente dos questionários, sendo, portanto, falas dos respondentes. 


\section{REVISTA ELETRÔNICA}

DA GRADUAÇÃO/PÓS-GRADUAÇÃ̃O EM EDUCAÇÃO

UFG/REJ

\section{ITNEPARIIS REFLECTIONIS}

ISS N. 1807-9342

Volume 14, N. 2, 2018

Quanto à escola confessional, a direção e a coordenação reconhecem a relevância dessa construção, no entanto, sem a participação dos diversos segmentos da comunidade escolar, para que as práticas sejam pautadas em um documento amplo e válido, dando a segurança de que estão agindo corretamente perante os objetivos a serem atingidos pela rede educacional. $O$ docente expõe que ele já vem pronto, não tecendo mais comentários. A resposta do docente e a falta de resposta dos outros três sinaliza que eles não conhecem o PPP como um todo. O máximo que parecem conhecer são tópicos dos projetos que devem ser executados no decorrer do ano, já que é a única coisa a que se referem.

A consciência de união e responsabilidade, tão importantes para demonstrar a força de uma instituição, não é salientada pelas escolas pública e confessional. As respostas são alheias, simples e diretas, a maioria delas demonstrando pouco conhecimento do PPP e da forma de trabalho em conjunto. Ademais, os docentes parecem trabalhar de forma desarticulada.

\section{O PPP EM PRÁTICA}

Quanto à possibilidade de colocar o PPP em prática na função que os participantes exercem atualmente na escola, todos os diretores reconhecem essa possibilidade. As respostas das escolas pública e confessional se assemelharam quando disseram que ele permite orientar suas ações para gerir de maneira correta a escola. $\mathrm{Na}$ instituição particular, o diretor afirmou que existe "um documento na escola que representa fidedignamente aquilo que realizamos, ou seja, existe um acompanhamento sistemático e organizado" (Informação verbal, 2017). Essa reflexão traz a ideia do que realmente o documento deveria ser para todos os profissionais da escola. No caso da direção, ele é utilizado para acompanhar os trabalhos dos outros segmentos, orientar toda a sua prática e a visão da escola como um todo integrado.

Entre os coordenadores, todos disseram ser possível executar o PPP. Foi salientado, pelo representante da escola pública, que isso é possível mediante os projetos desenvolvidos pela coordenação, de maneira conjunta entre professores e alunos. Na escola particular, um dos coordenadores escreveu de forma semelhante à direção da instituição pública. Já o segundo participante afirmou que o motivo reside no 


\section{REVISTA ELETRÔNICA \\ DA GRADUAÇÃO/PÓS-GRADUAÇÃOO EM EDUCAÇÃO}

UFG/REJ

\section{ITHEERAR IIS \\ REFLECTIONIS}

ISS N. 1807-9342

Volume 14, N. 2, 2018

fato de ser nesse momento que a instituição pode ser autônoma e adequar seu currículo para as práticas do professor em sala.

Na escola confessional, a coordenação só disse que ele é fundamental, mas não explicou mais nada. Essa desvalorização pode ser observada pela falta de conhecimento do documento. As respostas emitidas nos itens anteriores podem ter sido pautadas no que se ouve falar, mas, na prática, o professor não consegue identificar o que pode realmente ser feito.

Quanto aos docentes, nove deles disseram que é possível colocar o PPP em prática na sua função. Três da escola particular e dois da confessional reconhecem a relevância dele como orientador para a organização de um trabalho conjunto, a fim de atingir os objetivos da instituição da forma mais unida possível. Um docente da instituição pública salientou que os professores são a parte mais interessada na execução do PPP. Entretanto, percebendo-se a escola como um todo, o PPP é visto como importante para todos os segmentos. Não há uma parte principal na execução do documento. Se todos não se integrarem e se empenharem ele não orientará a prática de uma só função. Outro respondente da instituição pública que discorreu positivamente justificou que é possível colocá-lo em prática "desde que a equipe escolar esteja realizando-o de forma organizada, levando a sério em todo ano letivo" (Informação verbal, 2017). Essa ideia vem demonstrar a importância de executar um PPP em conjunto, pois não adianta um segmento sozinho tentar executá-lo. Em outra resposta, o sujeito afirmou não conhecer o PPP e explicou que tampouco participou de sua formulação, alegando que - embora reconheça que seja possível cumprir a regulamentação para a sua construção e relevância - percebe também que uma parcela de culpa é sua por não conhecer; a outra parcela é de instâncias superiores por não reservar um tempo para as reuniões pedagógicas. Na escola confessional, um docente afirmou que é possível e que desenvolve todos os tópicos contidos no Projeto. Entretanto, se esse sujeito disse conhecer o PPP de modo bem geral, pode não se atentar para os detalhes. Analisando essas considerações, como ele poderá desenvolver plenamente algo que não conhece? Isso expressa uma contradição entre seu conhecimento e sua ação.

Nos relatos dos respondentes, a teoria difere da prática. Pimenta (2012) salienta que só ocorre a real práxis educativa quando o professor consegue unir teoria e prática 


\section{REVISTA ELETRÔNICA \\ DA GRADUAÇÃO/PÓS-GRADUAÇÃOO EM EDUCAÇÃO}

UFG/REJ

\section{ITHERAPIIIS \\ REFLCTIONIS}

ISS N. 1807-9342

Volume 14, N. 2, 2018

em suas ações e, com isso, provoca transformações. Como se percebe, as instituições ainda passam por sérias dificuldades para conseguir essa união, já que muitas vezes a teoria é vista de forma independente da prática quando, na verdade, uma sustenta a outra.

\section{A INFluênCia do PPP NO PlANEJAMENTo E NA POSTURA DOCENTE EM SUA PRÁTICA PEDAGÓGICA}

O currículo é inserido no PPP e colocado em prática na sala de aula, fortalecendo a sua relevância. Buscou-se, assim, perceber como isso afeta o planejamento docente e sua postura em sala. A direção da escola pública não respondeu a essa questão. Levando-se em consideração que esse participante é uma pessoa experiente, com mais de vinte anos de profissão, certamente já esteve em sala. Além de dirigente, deveria saber como esse processo de transição entre a teoria escrita no PPP e sua interferência prática ocorre.

A coordenação da escola pública simplesmente colocou como resposta um "não", que não condizia com a questão apresentada, já que o objetivo era perceber como esse processo ocorre e não saber se ele ocorre, ou não. Isso demonstra a falta de interesse que muitos participantes têm em responder questões de pesquisas, assim como o descaso com que tratam o PPP na instituição. Pelas considerações feitas na parte que tange à prática, esse respondente o concebe como mero documento sistemático, engavetado. Entre os professores da instituição, três responderam e um não, por desconhecer o PPP pelo pouco tempo na escola. Todos que discorreram sobre a questão percebem a sua relevância para a prática em sala, como norteador de suas ações. Reconhecem que sem ele a orientação do trabalho se torna mais difícil. Um dos docentes enfatiza, ainda, que ele é importante para as práticas dentro e fora da sala. Outro, ao mesmo tempo em que reconhece o PPP como um norte para a sua prática, alegou que não conhece o documento. Apesar de justificar não ter conhecimento, afirmou que é "nele que vamos encontrar o perfil da escola e a maneira e métodos de trabalho junto à comunidade escolar" (Informação verbal, 2017). Na teoria isso realmente acontece, mas se o indivíduo desconhece o documento está assumindo que trabalha de maneira desarticulada dos demais. 


\section{REVISTA ELETRÔNICA \\ DA GRADUAÇÃO/PÓS-GRADUAÇÃOO EM EDUCAÇÃO}

UFG/REJ

\section{ITHEERAPIIIS \\ REFLCTIONIS}

ISS N. 1807-9342

Volume 14, N. 2, 2018

Entre os respondentes da escola particular, eles foram unânimes em afirmar que o planejamento ocorre com base no PPP, de maneira a orientar a prática em prol dos objetivos em comum. Entretanto, além da direção, um representante da coordenação e dois professores inclúram, em suas falas, o "Manual da Família", uma síntese do PPP entregue às famílias e aos funcionários para que todos saibam como agir para um trabalho coletivo e eficaz. Esse incentivo de unir família e escola em todo o processo de elaboração e entregar um modelo resumido do planejamento para que ela ajude na avaliação e reformulações necessárias demonstra como a escola preza pelo apoio da família e constante trabalho em conjunto. Já outro respondente da coordenação disse que essa influência ocorre através do plano de ação, para que sejam seguidas as diretrizes que a escola insere no documento. Somente se direcionando por ele os docentes conseguem aliar, ao processo de aprendizagem, o uso de tecnologias e a família conjuntamente.

$\mathrm{Na}$ instituição confessional, quatro respondentes (direção, coordenação e dois professores) comungam a ideia de que o PPP norteia o planejamento para que não ocorram falhas, já que as ações são realizadas com os alunos. O sujeito da direção, entretanto, argumentou, ainda, que é para que os planejamentos não ocorram fora dos parâmetros legais, o que mais uma vez evidencia a visão teórica do PPP. A falta de respostas entre os docentes justifica-se pelo fato de não conhecerem o documento, por isso não o utilizam na prática. Assim como os demais respondentes, eles apresentam apenas a dimensão teórica do PPP.

\section{PARTE MAIS RELEVANTE DO PPP PARA O TRABALHO PEDAGÓGICO}

Apesar do PPP dever ser percebido como um todo integrado, buscou-se identificar se existe mais relevância em algum tópico do documento em relação à aplicação na prática profissional ou algo que mais identifique a função. Quando questionados quanto a esse aspecto, a direção da escola pública não respondeu, assim como o docente que desconhece o PPP. O fato de desconhecer ou se desinteressar pelas perguntas pode justificar a atitude do sujeito da direção.

A coordenação e os dois docentes da escola pública identificaram o tópico dos projetos pedagógicos como mais relevantes para seu trabalho. Um dos professores disse 


\section{REVISTA ELETRÔNICA \\ DA GRADUAÇÃO/PÓS-GRADUAÇÃOO EM EDUCAÇÃO}

UFG/REJ

\section{ITHERARIIIS \\ REFLECTIONIS}

ISS N. 1807-9342

Volume 14, N. 2, 2018

que o fato se justifica por ser esse o ponto que define as ações e atividades que ocorrerão em sala, ou seja, ele é o norteador das práticas pedagógicas. Outro docente, entretanto, não especificou nenhuma parte como importante, explicando que "todas são como um elo de ligações onde não pode pular nenhum, pois pode causar desvio" (Informação verbal, 2017). Essa é a ideia da instituição que mais se assemelha à visão dos estudiosos sobre o tema.

A instituição particular foi a que teve mais heterogeneidade nas respostas. Para a direção e um dos sujeitos da coordenação, o mais relevante é o modo democrático de construção e o diálogo que se abre no momento dessa construção, que enriquece as práticas e a visão formadora da escola e seu papel na construção de seres conscientes para agir na sociedade. O outro representante da coordenação diz que a principal parte é a organização do trabalho pedagógico, que ocorre tanto na escola como um todo integrado quanto na coordenação das salas de aula, trazendo uma visão geral e individual simultaneamente.

Cada docente da instituição particular reconhece, de forma distinta, um tópico como principal. Um deles apontou a parte que relaciona os temas transversais, pois tem uma visão interdisciplinar que colabora para uma formação crítica dos educandos. Segundo ele, a união que se pode realizar entre as disciplinas enriquece os conteúdos, percebendo-os como um todo. O outro respondente do mesmo segmento salientou as diretrizes pedagógicas como importantes, pois é onde pode encontrar os objetivos da escola, assim como dados atualizados que favorecem o processo de ensino. Essa diversidade encontrada nesse segmento permite mais informações para seu planejamento. Já o terceiro professor disse que ele deve ser visto como um todo, pois uma parte complementa a outra e somente com a visão completa pode-se executar um bom planejamento mediante as diretrizes e concepções que a escola segue.

De modo geral, a escola tem uma boa ideia do PPP e de suas partes, que interferem diretamente no planejamento das ações que os profissionais devem ter para que cumpram os objetivos educacionais, atendendo os estudantes da forma mais adequada possível, com união entre os funcionários.

$\mathrm{Na}$ escola confessional, houve somente um questionário da coordenação e um docente com respostas quanto à parte ou tópico mais importante do PPP. Os demais omitiram suas respostas, fato que pode ser justificado pelo desconhecimento do 


\section{REVISTA ELETRÔNICA}

DA GRADUAÇÃO/PÓS-GRADUAÇÃ̃O EM EDUCAÇÃO UFG/REJ

\section{ITEERAMU REFLECTIONIS}

ISSN. 1807-9342

Volume 14, N. 2, 2018

documento. $\mathrm{O}$ respondente da coordenação disse que a parte principal para seu trabalho é a fase de avaliações, sem mais delongas. Um professor apontou os projetos, pois é no que se baseia para o planejamento da aula. Percebem-se opiniões contraditórias quando as questões práticas aparecem. Malheiro (2005) afirma que o fato de existir tanta burocracia faz com que o PPP seja tratado apenas como mais uma delas, sem que haja real reconhecimento de seu valor.

\section{A FLEXIBILIDADE DO PPP EM SUA PRÁTICA DOCENTE}

O PPP deve ser um documento flexível, que permita planejamentos diversificados e que contemplem a mesma finalidade. Quanto a essa plasticidade em sua execução na prática do professor, a direção da escola pública não respondeu à questão. Ao analisar que quando se passou para as questões da dimensão prática do documento o sujeito não contestou mais as perguntas, nota-se que seu conhecimento relativo ao tema se encontra limitado às teorias. Na visão do coordenador, essa possibilidade de adequação ocorre em alguns aspectos, mas ele não justifica sua resposta. Ao relembrar que ele disse que o PPP não é um documento adaptável, pode-se concluir que o percebe meramente como burocrático, e não passível de prática.

Todos os docentes responderam à questão relacionada à flexibilidade do PPP, concordando que ele norteia as ações pedagógicas que se deve ter na instituição, possibilitando noções para que o professor crie e recrie as teorias existentes visando o contexto e as possibilidades que os estudantes possuem, adaptando-se constantemente. Em relação à resposta do docente que não conhece o PPP e só respondeu quatro das doze questões, na maioria delas somente dizendo não conhecer e justificar que é pelo fato de não trabalhar há muito tempo na instituição, tem-se uma inconsistência. Se o sujeito diz que "é através dele que nós, professores, observamos a realidade dos alunos e adaptamos as tarefas conforme o dia a dia do estudante" (Informação verbal, 2017), subentende-se que a prática desse profissional está conscientemente defasada, uma vez que supostamente ele não consegue adaptar atividades ao contexto de seus discentes por não conhecer a realidade em que vivem.

Para os respondentes de todos os segmentos da escola particular, unanimemente, a maior fonte de enriquecimento da prática do professor reside no fato de apresentar 


\section{REVISTA ELETRÔNICA}

DA GRADUAÇÃO/PÓS-GRADUAÇÃ̃O EM EDUCAÇÃO UFG/REJ

\section{ITHERAPIIIS REFLECTIONIS}

ISSN. 1807-9342

Volume 14, N. 2, 2018

projetos interdisciplinares com eixos transversais, que possibilitem aos estudantes um aprendizado mais completo e rico se comparado ao trabalho de maneira isolada, como ocorre normalmente.

As considerações referentes à questão foram pequenas na escola confessional, uma vez que a direção e dois professores não contestaram o questionário. A resposta da coordenação baseou-se em um simples "sim", concordando que permite flexibilidade, entretanto, desconhecendo como isso de fato ocorre na prática. Já os dois docentes disseram que o PPP é o manual que eles consultam para elaborar suas ações, percebendo-o como algo inflexível.

\section{A PERCEPÇÃO DO PPP E SUA PRÁTICA NA INSTITUIÇÃO}

Outro ponto analisado relativo à relevância do PPP foi a percepção para a prática na instituição. Como ocorreu em boa parte do questionário, os sujeitos da direção da escola pública e confessional não responderam. Isso estabelece que o documento na realidade não interfere na prática do diretor na escola. Ele simplesmente pega o PPP para modificar a data no ano seguinte e o apresenta à instância superior ou a pessoas que vierem questionar a respeito, dando a impressão de que o mantém engavetado durante o período letivo.

O coordenador da escola pública respondeu um "sim", demonstrando sequer ter lido a questão. Esse descaso encontrado em muitas das respostas evidencia o modo como a educação brasileira se encontra. $\mathrm{Na}$ maioria das vezes o pesquisador é visto como um incômodo. As respostas só aparecem para dizer que a escola participa, entretanto, não se presta a devida atenção à qualidade das contestações. Isso ocorre, sobretudo, quando é um tema pouco pesquisado e de certa forma complexo, que ainda sofre incoerências de prática e aplicação.

Entre os quatro respondentes professores da escola pública, três disseram que o PPP significa um norte no qual podem se basear para formular suas práticas, suas ações, para que sejam condizentes e melhorem a qualidade do trabalho pedagógico ofertado pela instituição, assim como a formação de uma consciência crítica. O quarto sujeito embora admita não conhecer o documento em questão - reconhece que ele é muito importante para sua atuação no papel de educadora. Considerando essa colocação de 


\section{REVISTA ELETRÔNICA \\ DA GRADUAÇÃO/PÓS-GRADUAÇÃOO EM EDUCAÇÃO}

UFG/REJ

\section{ITHEERARIIIS \\ REFLECTIONIS}

ISS N. 1807-9342

Volume 14, N. 2, 2018

que o PPP orienta seu trabalho, mas admitindo, ao mesmo tempo, não conhecê-lo, sua prática pode parecer mais incoerente do que realmente deveria ser, pois o desconhecimento deixa a desejar. Para Resende (2008), o conhecimento deve ser construído por meio de uma didática dinâmica e a falta dele para fazer isso de maneira adequada à clientela de alunos da sala faz com que o processo ocorra de forma deficiente, não atingindo corretamente o estabelecido.

Das considerações realizadas pela direção, um coordenador e os professores da escola particular possuem a concepção de que o PPP é o norteador de sua prática e permite o diálogo e a tomada de decisões mais conscientes e condizentes. Admitem que ele permite mudar o rumo da educação, já que possibilita constantes adequações e não acaba ao findar do ano, por considerá-lo um processo de constantes ajustes e aperfeiçoamento em uma prática pedagógica. $\mathrm{O}$ outro coordenador da instituição salienta que:

O PPP tem se apresentado como objeto de estudo na busca de um avanço na qualidade de ensino. Ele preocupa-se em propor uma forma de organizar o trabalho pedagógico, visando a superação dos conflitos, buscando melhorar as relações competitivas, corporativas e autoritárias, na tentativa de acabar com a rotina do mundo interno da escola (Informação verbal, 2017).

A consciência crítica sobre o PPP enriquece a prática profissional. Suas ações tornam-se mais conscientes e pautadas em um documento que demonstra de fato a identidade da escola. Questionou-se a respeito da visão do conhecimento sobre o documento e sua aplicação prática na instituição para que se atinjam melhores resultados.

$\mathrm{Na}$ escola confessional a direção e dois professores não responderam à questão. Esse é o reflexo do processo de construção adotado pela instituição. Além de não participarem da elaboração os docentes tampouco conhecem o PPP da escola, não tendo, portanto, parâmetros para a explanação da parte prática que é elaborada. Assinalaram que é um manual para ser seguido e atingir os objetivos da escola. Sabe-se que um manual é algo estático, não passível de reformulações individuais e adequações, para todos. Fica, assim, percebido que o PPP dessa instituição é estático e somente é repassado aos professores o que devem fazer e como, não havendo uma reflexão a respeito das questões presentes. De modo geral, pode-se notar que a única instituição 


\section{REVISTA ELETRÔNICA \\ DA GRADUAÇÃO/PÓS-GRADUAÇÃOO EM EDUCAÇÃO}

UFG/REJ

\section{ITHEERAR IIS \\ REFLCTIONIS}

ISS N. 1807-9342

Volume 14, N. 2, 2018

que conhece o seu PPP e reconhece sua importância para as práticas é a escola particular. Um dos docentes também demonstra ter consciência do documento e sua real função em suas práticas pedagógicas e institucionais.

$\mathrm{O}$ índice de profissionais da educação ligados diretamente à prática pedagógica $\mathrm{e}$ administrativa que desconhecem o PPP, tendo somente noção de sua dimensão teórica, é considerado alto. A falta de conhecimento e até mesmo a falta de vontade são critérios percebidos na fala dos professores. Muitas escolas, além de não cumprirem efetivamente a LDB n 9.394 (BRASIL, 1996), não colocam o PPP em prática de maneira correta. Isso reflete que não há práxis pedagógica nessas instituições, já que não conseguem aliar teoria e prática de forma simples e clara para que haja a transformação no meio educativo.

\section{CONSIDERAÇÕES FINAIS}

$\mathrm{Na}$ relação entre as referências consultadas e as respostas dos pesquisados ocorreram muitas disparidades. Pode-se perceber, de maneira geral, que nenhuma das instituições executa de maneira coerente a construção do PPP. A dificuldade de uma formulação participativa é unânime e nenhuma das escolas consegue cumprir integralmente o planejamento participativo, envolvendo direção, coordenação, pais, alunos, servidores e pessoas da comunidade.

Entre as instituições pesquisadas, a que mais apresentou consenso e demonstrou mais conhecimento do tema proposto foi a escola particular. Nela todos os participantes, indiferente da função que desempenham, tiveram as respostas mais próximas do esperado. Um fato que deixa a desejar é a participação dos servidores da instituição nesse momento. Ainda assim, pode-se perceber que o modo como o documento é construído e efetivado faz com que os profissionais sigam a mesma direção em seu trabalho.

A instituição pública se depara com problemas de desconhecimento do PPP pelos professores, direção e coordenação. Muitas perguntas foram deixadas em branco ou tiveram respostas dadas de forma desatenta. Coordenação e direção demonstram não dedicar a atenção pedida no momento de relatarem seus conhecimentos. Por mais que alguns sujeitos possuíssem conhecimentos teóricos referentes ao documento, no 


\section{REVISTA ELETRÔNICA \\ DA GRADUAÇÃO/PÓS-GRADUAÇÃO EM EDUCAÇÃO}

UFG/REJ

\section{ITINERPARUS \\ REFLECTONIS}

ISSN. 1807-9342

Volume 14, N. 2, 2018

momento de discorrer sobre a prática efetivada em sua função não sabiam discernir, acabando por se contradizer ou simplesmente deixar de responder as questões.

Já a escola confessional foi a que mais se distanciou do que seria um PPP dentro das normas legais. Entre os participantes somente os representantes da direção e da coordenação disseram conhecer o documento. Os professores não o conheciam ou apenas haviam visto fragmentos dele, mas a construção não é coletiva. $\mathrm{Na}$ realidade, nem mesmo foi realizada na unidade escolar, o que o distancia ainda mais do contexto social da escola. Por não conhecerem ou perceberem somente suas partes tanto os docentes quanto a direção e a coordenação não sabiam discorrer em relação à prática do PPP em suas funções.

Por mais que a escola tenha autonomia, se não souber utilizá-la na construção de seu PPP, o momento rico de troca de conhecimentos e aprendizagens se perde. É por aí que se tem a noção de que não vale a pena somente ir a reuniões para discutir e até mesmo ler o documento após ser finalizado. Os funcionários da escola precisam ter em mente que o documento deve ser aplicável, pautando-se em constantes avaliações para melhorar e enriquecer o trabalho desenvolvido e, consequentemente, seus resultados.

É preciso que haja, urgentemente, mais conscientização de pais e estudantes para que participem do momento de construção do PPP, assim como uma convocação aos servidores. Se todos dependem e participam da escola, com certeza percebem os erros e acertos que ela possui e, por isso, todos devem participar de forma consciente e colaborar para a melhoria de um ambiente tão necessário para melhorar a vida social e individual. A ideia não é formar seres que criticam sem saber o que, ou simplesmente sejam máquinas de produção. O poder de argumentar e saber lutar pelos ideais individuais e coletivos começa na participação coletiva na escola.

\section{REFERÊNCIAS}

BOTELHO, Arlete de Freitas. Intencionalidades e efeitos da autoavaliação institucional na gestão de uma universidade multicampi. 2016. Tese (Doutorado em Educação) - Universidade de Brasîlia, Brasîlia, 2016. Disponível em: <http://repositorio.unb.br/handle/10482/20027>. Acesso em: 20 jul. 2017.

BRASIL. Lei no 9.394, de 20 de dezembro de 1996. Lei de Diretrizes e Bases da Educação Nacional. Estabelece as diretrizes e bases da educação nacional. Diário Oficial da União, Brasîlia, DF, 20 dez. 1996. 


\section{REVISTA ELETRÔNICA \\ DA GRADUAÇÃ O/PÓS-GRADUAÇÃO EM EDUCAÇÃO UFG/REJ}

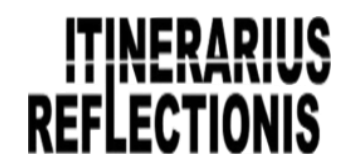

ISS N. 1807-9342

Volume 14, N. 2, 2018

GARCIA, Luciane Terra dos Santos. Projeto político-pedagógico: instrumento da ação na Escola Municipal Ascendino de Almeida. 2004. Dissertação (Mestrado em Educação) - Universidade Federal do Rio Grande do Norte, Natal, 2004. Disponível em: <https://repositorio.ufrn.br/jspui/bitstream/123456789/14257/1/Luc iane TSG.pdf> Acesso em: 29 set. 2016.

HORTA, Eduardo Duarte; RAMIRES, Elida Maia; DAVID, Marcus Vinicius. Recursos descentralizados para as escolas públicas: o caso do Estado de Goiás. In: HORTA, Eduardo Duarte; RAMIRES, Elida Maia; DAVID, Marcus Vinicius. Gestãoe avaliação da educação pública: avaliação e indicadores educacionais e políticas públicas e escola. Goiânia, GO: CAED, 2010. p. 47-63.

MALHEIRO, João. Projeto Político-Pedagógico: utopia ou realidade? Ensaio: avaliação de políticas públicas - Educação, Rio de Janeiro, v. 13, n. 46, p. 79-104, jan./mar. 2005. Disponível em:

<http://www.scielo.br/pdf/ensaio/v13n46/v13n46a05.pdf>. Acesso em: 29 set. 2016.

MARCONI, Marina de Andrade; LAKATOS, Eva Maria. Fundamentos de metodologia científica. 5. ed. São Paulo: Atlas, 2003.

MEDEL, Cássia Ravena Mulin de Assis. Projeto político-pedagógico: construção e implementação na escola. Campinas, SP: Autores Associados, 2008.

NEVES, Carmen Moreira de Castro. Autonomia da escola pública: um enfoque operacional. In: VEIGA, Ilma Passos Alencastro (Org.). Projeto político-pedagógico: uma construção possível. 24. ed. Campinas, SP: Papirus, 2008. p. 95-129.

PIMENTA, Selma Garrido. Estágio na formação de professores: unidade teoria e prática? 11. ed. São Paulo: Cortez, 2012.

RESENDE, Lúcia Maria Gonçalves de. Paradigma - Relações de poder - Projeto Político-Pedagógico: dimensões indissociáveis do fazer educativo. In: VEIGA, Ilma Passos Alencastro (org.). Projeto político-pedagógico: uma construção possível. 24. ed. Campinas, SP: Papirus, 2008. p. 53-94.

RIOS, Dermival Ribeiro. Minidicionário escolar da língua portuguesa. São Paulo: Difusão Cultural do Livro, 1999.

SANCHES, Raquel Cristina Ferraroni. Avaliação institucional e projeto pedagógico: articulação imprescindível. 2007. Tese (Doutorado em Educação) - Faculdade de Filosofia e Ciência, Universidade Estadual Paulista, Marília, 2007. Disponível em: $<$ https://www.marilia.unesp.br/Home/Pos-

Graduacao/Educacao/Dissertacoes/sanches_rcf_dr_mar.pdf $>$. Acesso em: 13 jun. 17.

VEIGA, Ilma Passos Alencastro. Projeto Político Pedagógico da Escola: uma construção coletiva. In: (Org.). Projeto político-pedagógico: uma construção possível. 24. ed. Campinas, SP: Papirus, 2008. p. 11-35. 